\title{
A ESCOLA NA VISÃO DOS ESTUDANTES DA EDUCAÇÃO DE JOVENS E ADULTOS: NARRATIVAS E PERSPECTIVAS
}

\author{
João Davi Avelar Pires ${ }^{1}$ \\ Regina Célio Alegro ${ }^{2}$
}

Resumo: Tendo por base a valorização e a importância que se tem dado aos conhecimentos prévios, anteriores ao ensino formal, e às narrativas dos estudantes nas últimas décadas, este trabalho apresenta uma sucinta análise de narrativas colhidas entre frequentadores da Educação de Jovens e Adultos (EJA) em cidades do norte paranaense. Tentamos identificar as ideias, concepções e representações que estes possuem sobre a escola e o espaço escolar considerado como ideal, bem como sua finalidade, as relações sociais que se estabelecem e o público para o qual a instituição escolar se destina. Trabalhamos, portanto, com narrativas de estudantes enquanto um tipo de linguagem, escrita, construída através da memória e também de construções e reconstruções pessoais, que podem nos fornecer indícios do que eles pensam e de que tipos de interpretação possuem. Entendemos como característica principal da narrativa seu esforço construtivo, na medida em que pensamentos, interpretações e representações sociais que se encontram presentes na estrutura cognitiva do sujeito devem ser sistematizados e ordenados, numa escrita que faça sentido e que consiga apresentar determinada visão de mundo. Destas narrativas, foram criadas categorias, a partir de aspectos comuns, e divididas por representações sobre a escola, finalidades da escola e relações entre alunos e professores.

Palavras-chave: Escola. Educação de jovens e adultos. Representação social.

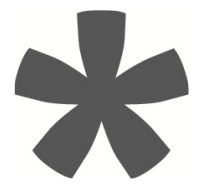

${ }^{1}$ Mestre em História Social pela Universidade de Londrina. E-mail: joaodavi_ap@hotmail.com

2 Doutora em Educacao pela Universidade Estadual Paulista Júlio de Mesquita Filho. Atualmente é Professora adjunto da Universidade Estadual de Londrina.. E-mail: alegro@uel.br 


\section{SCHOOL IN THE VISION OF THE STUDENTS FROM YOUTH AND ADULT EDUCATION: NARRATIVE AND PROSPECTS}

Abstract: Based on the growing valuation and importance of prior knowledge, prior to formal education, and of the narratives of students in recent decades, this work presents a brief analysis of narratives collected from visitors of the Education of Youth and Adult (EYA) in cities in the north of Paraná. We tried to identify the ideas, concepts and representations they have about the school and the school environment considered being ideal as well as its purpose, social relations established, and the public to whom the educational institution is intended. We work therefore with narratives of students as a type of language, writing, constructed by memory and also by personal constructions and reconstructions, which can provide us with indications of what they think and what kinds of interpretation they have. We understand as a main feature of the narrative its constructive endeavor, insofar as thoughts, interpretations and social representations present in the cognitive structure of the subject should be systematized and ordered in a writing that makes sense and that can present a particular worldview. Categories were created out these narratives, from their commonalities, and divided by representations on the school, school purposes and relations between students and teachers.

Keywords: School. Education of youth and adults. Social representation.

\section{LA ESCOLA SEGÚN LA VISIÓN DE LOS ESTUDIANTES DE EDUCACIÓN PARA JOVENES Y ADULTOS: NARRATIVAS Y PERSPECTIVAS}

Resumen: Con base en la valoración y la importancia que se ha dado al conocimiento previo, antes de la educación formal, y las narraciones de los estudiantes en las últimas décadas, este trabajo presenta un breve análisis de los relatos recogidos de los frecuentadores de la Educación de Jóvenes y Adultos (EJA) en las ciudades del norte de Paraná. Tratamos de identificar las ideas, conceptos y representaciones que tienen sobre la escuela y el entorno escolar considerado ideal, así como su finalidad, las relaciones sociales establecidas y el público al que se destina la institución educativa. Trabajamos por tanto, con las narraciones de los estudiantes como una especie de lenguaje, escritura, construido por la memoria y también construcciones y reconstrucciones personales, que pueden proporcionar la evidencia de lo que ellos piensan y qué tipo de interpretación tienen. Entendemos como principal característica de la narrativa, el esfuerzo constructivo, en la medida en que pensamientos, interpretaciones y representaciones sociales que están presentes en la estructura cognitiva del sujeto deben ser sistematizadas y ordenadas en una escritura que tiene sentido y que puede presentar una determinada visión de mundo. De estas narrativas, surgieron categorías fueron creados a partir de elementos comunes y se dividen en representaciones de la escuela, propósitos de la escuela y relaciones entre estudiantes y profesores.

Palabras clave: Escuela. Educación de Jóvenes y Adultos. Representación social.

Educ. Anál., Londrina, v.1, n.1, p. 111-132, jan./jul. 2016 


\section{Introdução}

Neste trabalho, analisamos narrativas de 64 alunos, sendo 33 homens e 31 mulheres, pertencentes às zonas rural e urbana das seguintes cidades do Norte Velho paranaense: Bandeirantes, Barão de Antonina, Candói, Curiúva, Figueira, Guapirama, Ibaiti, Jacarezinho, Japira, Joaquim Távora, Santana do Itararé e Sapopema.

As idades dos alunos variam dos 14 aos 67 anos, o que demonstra a heterogeneidade do grupo, fato reforçado pelas áreas de moradia e também pelas profissões. Entre as profissões mais comuns aparecem a de empregada doméstica, agricultor, aposentado, campeiro, comerciante, costureira, funcionário público, estudante, lavrador, leiteiro, motorista, operador de máquinas, servente, vendedor, zeladora, tratador e as relacionadas à mineração.

A importância deste estudo se concentra no fato de que as informações e as análises aqui realizadas partem das ideias dos próprios alunos em relação à escola e ao espaço escolar. Vale ressaltar que esses estudantes são adultos e frequentam a Educação de Jovens e Adultos (EJA).

É importante destacar que as pesquisas realizadas no âmbito do Ensino, que analisam as idéias e conhecimentos de alunos, privilegiam crianças e adolescentes, deixando de lado as ideias e as experiências dos adultos.

Essas ideias e conhecimentos prévios que os alunos possuem estão diretamente relacionados às representações sociais, na medida em que estas se apresentam como

[...] uma maneira de pensar e interpretar a realidade cotidiana, uma forma de conhecimento da atividade mental desenvolvida pelos indivíduos e pelos grupos para fixar sua posição em relação a situações, eventos, objetos e comunicações que lhe concernem [...] (SÊGA, 2000, p. 128).

O contexto social pode intervir nessas representações através dos lugares onde se situam os grupos e os indivíduos, pela comunicação que se estabelece entre eles, pelo quadro de apreensão que lhes fornece sua bagagem cultural, códigos, símbolos, valores e ideologias que estão ligados a posições e vinculações sociais específicas. 
O conhecimento prévio do aluno é influenciado por todo esse contexto e por essas representações, sua visão de mundo e da realidade vai depender do meio em que vive e dos conhecimentos, valores e códigos que recebeu do grupo do qual participa. Seja para aceitá-los ou refutá-los, os conhecimentos prévios e as ideias dos alunos são inseparáveis de seu meio social. Esses conhecimentos ou representações sociais é que dão sentido aos eventos que nos são normais. Ou seja, os conhecimentos prévios dos alunos são construções realizadas na dimensão das relações socioculturais.

De acordo com Ivo Mattozzi (1998), são variados os fatores que podem conformar a concepção prévia dos estudantes, e esta poderá ter a participação da ação pedagógica escolar como elemento desestabilizador ou não, além, evidentemente, do que trazem de outros contextos para a escola, que também podem ajudar, ou não, a atuar numa perspectiva crítica.

Melo (2003) mostrou que os alunos têm ideias tácitas sobre acontecimentos e instituições históricas e que essas ideias funcionam como uma fonte de hipóteses explicativas para compreender o passado, as instituições, os valores, as crenças e os comportamentos. 0 professor deve demonstrar ao aluno o que este sabe, para planejar situações de aprendizagem em que os saberes possam ser confrontados.

\section{O Instrumento de Pesquisa}

Para que alcançássemos nosso objetivo inicial, ou seja, a coleta de narrativas de estudantes sobre qual seria, para eles, a escola ideal, optamos pela utilização de um instrumento e pesquisa em que houvesse liberdade para que fossem expostas as prerrogativas desse tipo de escola. Dessa forma, pareceu-nos adequado que os estudantes apresentassem suas ideias a partir de um texto, sem direcionamentos prévios, apenas tendo como foco as características que uma escola ideal deveria possuir.

Dessa maneira, foi pedido para que eles produzissem um texto dissertativo, tendo como escopo a seguinte questão: “Qual seria, para você, a escola ideal?". Todos os textos e narrativas coletados foram rigorosamente categorizados e analisados, seguindo os pressupostos da Análise Textual Qualitativa, proposta por Roque Moraes (2003). 


\section{A Análise Textual Qualitativa}

Roque Moraes (2003) trata das maneiras possíveis e confiáveis de realizar uma análise baseada em ideias de alunos, partindo dos princípios de desmontagem dos textos, estabelecimento de relações entre ideias comuns e, por fim, a análise, para a compreensão do que os alunos entendem e como eles percebem e se relacionam com determinado assunto. De acordo com Moraes (2003, p. 195), a primeira etapa, a desconstrução e unitarização do corpus, ou seja, das análises coletadas, consiste num processo de desmontagem ou desintegração dos textos, destacando seus elementos constituintes. Implica colocar o foco nos detalhes e nas partes componentes, um processo de divisão que toda análise implica. Com essa fragmentação ou desconstrução dos textos, pretende-se conseguir perceber os sentidos dos textos em diferentes limites de seus pormenores, ainda que compreendendo que um limite final e absoluto nunca é atingido. É o próprio pesquisador que decide em que medida fragmentará seus textos, podendo daí resultar unidades de análise de maior ou menor amplitude. Da desconstrução dos textos surge o que Moraes define como as "unidades de análise, unidades de significado ou de sentido" (MORAES, 2003, p. 195).

A unitarização, ou seja, a desmontagem dos textos, implica examinar os materiais em seus detalhes, fragmentando-os no sentido de atingir unidades constituintes, enunciados referentes aos fenômenos estudados. A categorização e o estabelecimento de relações implicam na construção de relações entre as unidades de base, combinando-as e classificando-as no sentido de compreender como esses elementos unitários podem ser reunidos na formação de conjuntos mais complexos, as categorias. Os materiais analisados constituem um conjunto de significantes, aos quais o pesquisador atribui significados sobre seus conhecimentos e teorias. A emergência e comunicação desses novos sentidos e significados é o objetivo da análise.

As unidades de análise são sempre definidas em função de um sentido pertinente aos propósitos da pesquisa, que, no caso deste trabalho, é identificar e analisar o que os alunos entendem por escola ideal e a partir de onde elaboraram esse conhecimento. 
A fragmentação dos textos é concretizada por uma ou mais leituras, identificando e codificando cada fragmento destacado, resultando daí as unidades de análise. Cada unidade constitui um elemento de significado referente ao fenômeno que está sendo investigado. Finalmente, para facilitar o passo seguinte da análise, a categorização, é interessante atribuir a cada unidade de análise, assim construída, um título que deve apresentar a ideia central da unidade.

O segundo passo da análise é a categorização, um processo de comparação constante entre as unidades definidas no processo inicial da análise, levando a agrupamentos de elementos semelhantes. Os conjuntos de elementos de significação próximos constituem as categorias.

A categorização, além de reunir elementos semelhantes, também implica nomear e definir as categorias. O método indutivo implica construir as categorias com base nas informações contidas no corpus. Por um processo de comparação e contrastação constantes entre as unidades de análise, o pesquisador vai organizando conjuntos de elementos semelhantes, geralmente com base em seu conhecimento tácito. Esse é um processo essencialmente indutivo, de caminhar do particular ao geral, resultando no que se denomina as categorias emergentes (MORAES, 2003, p. 197).

Um conjunto de categorias só é válido quando é capaz de representar adequadamente as informações categorizadas, atendendo, dessa forma, aos objetivos da análise, que é de melhorar a compreensão dos fenômenos investigados. É importante para tal tarefa a obra de Ginzburg (1990), que diz que nos fatos mais negligenciáveis, encontramos as respostas mais abrangentes. Para ele, muitos saberes são como o do médico, que investiga os sintomas, e, assim como ele, muitos outros saberes indiciários produzem um conhecimento lendo e interpretando os sinais, as pistas e os indícios. É importante dizer que este estudo abrange apenas uma pequena amostra, então seus resultados não podem se generalizar a uma população maior.

Em relação aos alunos, foi pedido para que redigissem um texto sobre qual seria a escola dos seus sonhos. O enunciado dizia: "Escreva um texto no qual você nos conta como é a escola dos seus sonhos". 
Após a desconstrução e desmontagem dos textos, organizamos as ideias em categorias, que, para Laurence Bardin (1977, p. 117), são “uma operação de classificação dos elementos constitutivos de um conjunto por diferenciação, e pelo seu agrupamento a partir de critérios previamente definidos".

Para fins de organização e exposição das análises, optamos por um sistema de identificação dos estudantes e de suas narrativas. Os estudantes foram enumerados entre os que se ativeram ao tema proposto e aqueles que não o contemplaram. Realizamos a identificação, também, a partir de suas idades e das iniciais de seus nomes e sobrenomes, para preservação da identidade dos participantes. Por exemplo, 1.18 J.N.C. O número 1 significa que o estudante se ateve ao tema proposto para a produção do texto, 18 se refere à idade do participante, e J.N.C. são suas iniciais.

\section{As Representações da Escola Ideal}

Essa categoria enquadra as ideias relacionadas ao que seria a escola ideal ou a escola sonhada pelos participantes da pesquisa ${ }^{3}$. As categorias foram feitas a partir de três eixos: como seria a escola ideal na visão do aluno; as funções que a escola deveria desempenhar; as relações entre professores e alunos. A partir desses três pontos principais, desenrolaram-se subcategorias, que serão detalhadas mais adiante.

\section{A Escola Enquanto Espaço Físico e Com Tecnologia Recente}

De um total de 64 narrativas, 22 relacionam o conceito de escola ao espaço físico e aos recursos que deveriam estar presentes nele. A questão da escola como um dos lugares onde acontece o aprendizado e a interação com o conhecimento não fica clara ou não aparece nesta linha de pensamento.

Como exemplares de narrativa que demonstram essa perspectiva da escola enquanto espaço físico, grande e espaçoso, com aparelhos de tecnologia atualizada, cito as narrativas dos alunos 1.18 J.N.C. e 1.58 T.R.M., respectivamente:

\footnotetext{
${ }^{3} \mathrm{O}$ formato da escrita dos estudantes foi mantido ao transcrever, inclusive os erros ortográficos.
} 
[...] que tenha mais teconologí as carteiras quadros se mais modernos para desevolver os Alunos a ir pra Escola, para também trazer mais alegria queria uma quadra de futebol bem mais grande queria que trousesse ar-condisionado para as salas de ala queria reformasse a Escola [...] P. 16 L. 478-480

A escola do meu sonho Eu queria que na minha escola tivesse um ventilador, um computador, e uma televisão, uma quadra para nos treinar vole, falta vidio cassete para poder aprender mais. P. 35 L. 1095-1096

Os dois trechos acima demonstram qual seria a escola ideal para eles. Nas 22 narrativas, a escola ideal, a escola com que eles sonham, seria um lugar grande, com mais salas de aula, mais espaçosas, com quadros e carteiras novos e mais espaçosos para que eles fiquem mais confortáveis. Pensam também nos professores, quando dizem que as escolas precisam de carteiras mais espaçosas para o professor trabalhar melhor e armários grandes para que ele possa guardar suas coisas de trabalho. Aparece também, nas narrativas, o desejo dos alunos por escolas com áreas de lazer mais bem preparadas, com quadras poliesportivas para treinar esportes diversos, inclusive piscinas para o uso dos alunos. Além das características acima, aparece também a questão da beleza da escola. Não basta que a escola seja grande e atualizada, ela precisa ser bonita, bem arrumada e, principalmente, limpa.

A questão da tecnologia também é frequente nas narrativas dos alunos. Em suas narrativas, aparece uma grande variedade de produtos e aparelhos eletrônicos, como computadores, videocassetes, ventiladores, aparelhos de ar condicionado, televisores, etc.

É interessante notar que, dentre todas as narrativas analisadas, apenas duas se referem à escola em que estudam como a escola ideal, e o fazem para compará-la com a que gostariam de ter. A escola que aparece nos textos é uma escola imaginada como sendo a que melhor atenderia as suas necessidades de aprendizagem. É importante discutir, nesse ponto, a importância que os alunos dão às questões relacionadas ao espaço físico da escola e às tecnologias de que ela dispõe como condições necessárias a uma melhor aprendizagem. Nas narrativas analisadas, os alunos citam a necessidade de equipamentos modernos para que, através deles, o professor possa trabalhar e ensinar melhor. 
Sabemos que a utilização dos recursos didáticos, como os aparelhos eletrônicos e de informática, com um fim em si mesmo, está longe de ser a solução para os problemas da educação. Eles devem ser utilizados juntamente com conteúdos potencialmente significativos para os alunos, para que através das discussões dos conteúdos, da utilização dos recursos e de atividades de reflexão e crítica, o conhecimento possa ser construído. Mas é importante ressaltar, também, que, pelo fato de os alunos estarem tratando de uma escola imaginada e sonhada, idealizada, eles não possuem esse tipo de escola.

É interessante perceber que estes 22 alunos parecem não perceber que a relações entre o ensino, a aprendizagem e as novas tecnologias são muito mais complexas do que parecem. De nada adianta uma escola com tecnologia atual e informatizada, se os profissionais da educação, ou seja, os professores, não conseguirem trabalhar com tais recursos ou não estiverem preparados para isso.

Mas pode se pensar a questão também a partir da experiência de vida dos alunos. A maioria deles pode não possuir computadores, televisores e outros aparelhos em casa, por isso acreditam que a escola, enquanto local de formação para a vida e principalmente formação profissional, devesse não somente disponibilizar a eles esses novos recursos tecnológicos, mas também ensinar a usá-los.

\section{A Escola Como Espaço Seguro}

Outra abordagem que aparece nas narrativas dos alunos é a questão da segurança relacionada à escola. Ou melhor, a escola aparece nas narrativas como um local de confiança, seguro, onde os pais poderiam deixar seus filhos com a garantia de que dentro desse espaço eles estariam salvos e seguros. Como exemplo dessa visão, apresentamos abaixo as narrativas dos alunos 1.65 C. e 1.67 D.C.:

[...] bom a escola eu gostaria que fosse segura fechada somente com o portão bem seguro sem perigo de entrar quauquer pessoa com más intenção que a gente mandava nossos filhos pra escola e ficacemos tranquilo porque muitos lugares existem muitos problemas com drogas brigas na frente da escola [...] P. 37 L. 1170-1172 
[...] É uma Escola mui compente para os meus filho muita segurança [...] Para meus filho uma educa uito boa e que teja mui seguraça porque na escola esiste mui coisa ruis porezenpro as drogas poriço quero o melhor para para todas as crianças porque quando nos filhos vai para a Escola nos que somos as mães ficamos muito preocupado pensando como será que meu filho esta eu sei que Deus esta com eles mas mesmo asim eu fico preocupada porque eu amo eles. P. 38 L. 11891194

As narrativas acima dão um exemplo de dois dos principais problemas que parecem ser as maiores preocupações dos alunos. O primeiro é a questão das drogas dentro e nos arredores da escola. Entre os alunos pesquisados, seis relacionam a segurança justamente ao impedimento da entrada de drogas e também das pessoas que a carregam e vendem, visto que o espaço escolar é onde seus filhos ficam durante uma grande parte do dia. No primeiro caso citado acima, o aluno nos diz claramente dos perigos relacionados a pessoas más intencionadas que têm acesso à escola, sejam eles alunos ou não.

Outro aspecto mencionado por esse aluno é a questão das brigas que frequentemente ocorrem dentro e fora das escolas. No espaço escolar, entre os muros da escola, muitas vezes as brigas são controladas por professores, diretores e, até mesmo, algumas vezes, por outras autoridades. Mas isso não impede que a briga continue fora do espaço escolar, até mesmo de formas mais violentas e agressivas, já que não há uma fiscalização e um controle tão rígido como nos locais escolares.

$\mathrm{Na}$ segunda narrativa, percebemos a preocupação de uma mãe em relação aos filhos. Os pais não podem permanecer o tempo todo na escola cuidando dos filhos, portanto o que eles esperam da escola enquanto uma instituição educacional é que seus filhos possam estudar com segurança e integridade, para que possam ficar despreocupados durante o período em que os filhos estão na escola.

\section{A Escola Como Lugar de Aceitação das Diferenças}

A questão das diferenças e da sua aceitação também aparece na narrativa de dois alunos, passando pela discriminação, desprezo, igualdade e racismo. As discussões acerca dessa temática, da tolerância e da aceitação 
das diferenças são essenciais para as escolas, visto que, nas escolas públicas, o público é heterogêneo, os alunos vêm das mais diversas regiões e bairros, centro e periferia, zona rural e zona urbana, etc. Portanto, as diferenças e a diversidade cultural e racial são evidentes nas escolas, e deve ser tratada em termos de igualdade, sem nenhum tipo de relação de superioridade ou inferioridade, nem de níveis qualitativos.

O preconceito racial não é recente no Brasil, vindo de séculos passados. Essas ideias pré-concebidas sobre a superioridade de alguns e a inferioridade de outros foram sendo incutidas na mentalidade ocidental durante décadas e séculos, e ainda hoje é frequente em nosso cotidiano. Portanto, esse problema também está presente em nossas escolas e deve ser enfrentado. Como exemplos, cito as narrativas dos alunos 1.64 Z.P.V.S. e 1.53 R.F., que deixam claras as suas preocupações:

A escola mini-ninho, é uma escola aonde todas as crianças fosse todas iguais, não havia nenhum tipo de despreso, todas as crianças se sentia iguais. Não havia discriminação, racismo entre cores, todas as crianças brincavam, estudavam juntos $e$ se sentia muito felizes [...] P. 37 L. 1054-1057

A escola dos meus sonhos deve ser uma Escola aonde não ouvesse descriminação entre as pessoas [...] P. 32 L. 1016

O racismo, o preconceito e a discriminação citados pelos alunos acima levam a outros tipos de comportamentos totalmente inadequados, criminosos e violentos para com os que são diferentes. Utilizando-se de ideias equivocadas e pré-concebidas, muitos discriminam baseando-se em diferenças de cor ou de gostos, comportamentos ou religião. É de suma importância que esse tipo de atitude seja combatido para que as escolas sejam um espaço democrático onde todos possam ter uma educação de qualidade e sem qualquer tipo de diferenciação, independentemente de sua cor ou de suas escolhas culturais. 


\section{A Escola Enquanto Local de Inclusão Infantil}

Um ponto interessante e passível de ser pensado é em relação às crianças que não frequentam a escola. Dois alunos relacionaram, ao que seria a escola dos seus sonhos, a inclusão dessas crianças neste espaço. Como já foi dito anteriormente, um espaço onde todos possam estudar com tranquilidade, em paz, com suas diferenças respeitadas e onde todas as crianças têm as mesmas oportunidades. Seguem as narrativas dos alunos 1.4 A.J. e 1.15 I.A.A., respectivamente:

[...] As escola do meu sonho é comtodas as crianças dentro da sala de aula não ficando narrua. P. 6 L. 176

[...] para que eu posso construir uma escola com dois andares para que possa todas essas crianças que morão na rua poder estudar nessa escola [...] P. 15 L. 448-449

Na primeira narrativa, o aluno se refere às crianças que não frequentam a escola pelas mais diversas razões, mas não dá a entender de que está se referindo a crianças que moram na rua, mas, sim, crianças que têm um lar que, mas não estão inclusas no espaço escolar.

A segunda narrativa dá outra visão sobre o que deveria ser a escola. Uma escola para acolher todas as crianças que moram na rua, para que possam ter as mesmas oportunidades de um ensino digno e de qualidade.

É interessante perceber como esses alunos idealizam a escola. Para eles, a escola seria responsável por uma série de competências diversas, de inclusão, respeito mútuo e igualdade. A impressão que se tem é de que a escola seria o lugar onde praticamente todos os problemas se resolvem, e, mesmo em um mundo tão violento como o que vivemos, a escola é, ou melhor, deveria ser o local onde as crianças encontrariam a segurança, a paz e a tranquilidade. Podemos inferir, a partir das narrativas, que a escola possui uma função redentora, apesar de não cumprir essa função.

Justamente por a escola ser um local de aprendizado e de crescimento, não só visando a formação profissional, mas também a pessoal e humana, é que a aceitação da diferença deveria ser um pilar importante para a formação recebida na escola. 


\section{A escola Como Um Lugar de Socialização}

Também aparece nas narrativas dos alunos a escola vista como o lugar onde acontece a socialização. Um total de nove alunos descrevem a escola como um local onde, além de aprender, eles encontram seus amigos, conversam sobre os mais variados assuntos e praticam os mais diversos esportes nas quadras esportivas por eles sonhadas.

Percebemos, nas narrativas dos alunos 1.61 V.B. e 1.23 J.M.C., elementos interessantes para serem pensados:

[...] todos os dias mi vejo a hora de ir a escola lá Eu encontrei amigos. Todos os alunos são otimo e legar [...] P. 36 L. 10251027

[...] Escola do saber podia de tudo brinca correr e esconder, uma escola alegre e divertida e animada [...] P. 17 L. 537

Nas duas narrativas acima, percebemos o caráter de sociabilidade destinado à escola. Na primeira, o aluno $1.61 \mathrm{~V}$.B. claramente se refere ao seu presente, à sua escola, para assim demonstrar qual seria a escola perfeita ou ideal. Para ele, a escola dos sonhos é aquela em que ele estuda, pois lá encontrou amigos que, de acordo com ele, são ótimos e muito legais.

$\mathrm{Na}$ segunda, percebemos o desejo de que as escolas sejam, além do espaço de socialização enquanto construtor de novas amizades e manutenção das já existentes, um espaço também onde as brincadeiras e as atividades lúdicas aconteçam a todo momento. Uma escola onde reine a alegria e animação. Esse tipo de abordagem aparece em diversas narrativas, todas relacionando a escola a esse espaço de diversão, com dezenas de brincadeiras, como esconde-esconde, pular corda, etc.

Esse tipo de atitude pode ser baseado em experiências de outra época, visto que todos ou pelo menos a grande maioria dos alunos examinados já passaram pela escola em algum momento de suas vidas e agora estão retornando. Assim, pelo menos uma grande parte desses alunos pode ter se baseado nessas experiências para dizer que a escola ideal seria a escola onde a liberdade de se divertir e de brincar fosse constante. 
Os alunos deveriam escrever sobre a escola dos seus sonhos. Portanto, ao descrever o que seria para eles a escola ideal, os alunos se baseiam em suas experiências passadas e presentes para definir e narrar as características dessa escola almejada. Partindo do pressuposto de que a escola da qual os alunos tratam em seus textos é uma escola idealizada e inventada, entendese que eles não possuem as comodidades por eles descritas.

\section{As Funções a Serem Desempenhadas Pela Escola Ideal}

Nesta categoria, foram selecionadas e analisadas as narrativas que demonstram, para esses alunos da EJA, quais funções a escola imaginada e idealizada por eles deveria desempenhar.

\section{A Escola Com Função Alfabetizadora}

A primeira subcategoria foi construída em torno das narrativas que tratam da escola como o local onde as crianças e as pessoas aprendem a ler e a escrever, que totalizaram seis narrativas. Não aparece nelas uma função muito mais abrangente, que ultrapasse os limites da alfabetização e forme pessoas com outros tipos de conhecimento. Seguem os exemplos dos alunos 1.15 I.A.A. e 1.47 R.J.S.: “[...] aonde você pode aprender muitas coisas como por exemplo ler, escrever [...]” P. 15 L. 451 “[...] porque os alunos vão aprender ler é na escola [...]” P. 29 L. 923

As duas narrativas são idênticas ou muito semelhantes a várias outras que identificam na alfabetização a principal ou mesmo a única função da escola. Podemos registrar aqui que a maioria dos alunos possui deficiências em sua escrita, talvez motivo de uma alfabetização descontinuada e fragmentada, o que pode caracterizar um dos motivos de sua volta à escola, depois de curtos ou longos períodos sem frequentá-la.

Os alunos demonstram uma grande preocupação com a leitura e a escrita, pois, como foi dito em outras narrativas anteriores, a escola é pensada como um lugar onde não há discriminação. A discriminação acontece também fora da escola, entre uma grande variedade de causas, contra pessoas que não sabem ler e escrever. Pensando nesta perspectiva, são 
inúmeros fatores que impulsionam as pessoas a voltar para a escola para completar sua alfabetização, como o desejo de ler e escrever corretamente, complementar sua formação, por exemplo, além de outros.

\section{A Escola Como Formadora de Valores}

Outro elemento importante que apareceu nas narrativas referentes às funções da escola foi o caráter de preparação para a vida, através do ensino de valores considerados importantes. Como nos dizem os alunos 1.15 I.A.A. e 1.36 M.A.R.B.: “[...] Pois a escola e um lugar aonde você pode aprender muitas coisas como [...] respeitar aos mais velho e um aos outro". P. 15 L. 451-452 “[...] Na escola a gente aprende a educação o respeito, o amor $e$ carinho e a paz". P. 23 L.707

Percebemos nas narrativas a função dada à escola por esse aluno, em concordância com vários outros textos. A escola enquanto formadora de caráter, de sentimentos bons e positivos como o amor, o carinho, o respeito para com os mais velhos, etc. Podemos fazer aqui uma relação entre esse ensino e aprendizado de valores, e a escola como um lugar de socialização, pois, para que essa socialização aconteça de forma harmoniosa, é preciso que se tenham esses valores, e se não os tiverem, a escola está lá para ensiná-los.

\section{A Escola e o Bom Emprego}

A escola enquanto preparação ou como garantia de um bom emprego é o ponto mais recorrente nas narrativas analisadas, visto que muitos deles retornaram à escola pensando nessa conquista do bom emprego. Do total de alunos, nove possuem essa perspectiva, como nos dizem os alunos 1.4 A.J. e 1.46 R.S: “[...] A escola é fundamental para conseguir um emprego [...]” P. 6 L. 174 “[...] importante sem o estudo a gente não consegue pegar um emprego [...]" P. 29 L. 895-896

Assim, este conceito de escola, ou melhor, a escola como a instituição que prepara e que garante o emprego, é recorrente nas narrativas dos estudantes. 0 mercado de trabalho, há algum tempo, já exigia um mínimo de escolaridade para desempenhar determinados empregos. Note-se também 
que, para muitos alunos, o emprego que eles querem conseguir, a partir da instrução, é um bom emprego, que, com toda certeza, necessita de um grau maior de alfabetização e escolarização. Alguns estudam para melhorar suas condições de vida atuais, neste caso os que já possuem um emprego, e os jovens, mesmo sendo poucos, almejam um bom emprego no futuro, e veem na escola uma oportunidade para que consigam ter seus sonhos realizados.

Outra função da escola diz respeito à mudança de vida, uma vida melhor e ser alguém na vida. Estes alunos não citaram em suas narrativas a questão do emprego, mas, por falarem de melhores perspectivas de vida no futuro, subentendemos que a maneira pela qual essa mudança ocorreria seria através da conquista de um bom emprego, estável, etc. para que assim ocorra o que eles esperam do futuro. Mas, para que isso ocorra, eles devem lutar, batalhar, e a escola é, então, o espaço de luta e de conquista, na medida em que retornam depois de anos longe dela e retomam seus estudos com o objetivo de alcançar esse futuro sonhado. É nesse contexto que a educação e a escola aparecem como portadoras de uma função salvadora, capaz de resolver todos os problemas.

\section{A Escola e a Merenda Escolar}

Ao tratar da questão da escola e de qual seria a ideal para nossos alunos, um ponto que frequentemente aparece, não só nas narrativas, mas também em discussões de outros âmbitos e setores, é a questão da merenda. Como exemplo, cito as narrativas dos alunos 1.28 M.O., e 1.21 J.S.J., respectivamente: "[...] Eu gosto de sopa e café com leite e tivesse esse lanche todos os dias [...]” P. 19 L. 588 “[...] que as refeições fossem mais saldaveis para nossas crianças [...]” P. 17 L. 512-513

A questão da merenda é frequente nas narrativas analisadas, que relacionam a escola ideal a um espaço, além de tudo o que já foi dito, ao lugar onde deveria ser dada merenda gostosa, de qualidade e saudável.

Sabemos que esses alunos ficaram, em sua maioria, muitos anos fora da escola, devido a motivos financeiros. A maioria era pobre e foi obrigada a abandonar a escola para trabalhar e ajudar com o sustento da família. Retornaram muito tempo depois, com uma alfabetização deficiente, na busca 
por melhorá-la. Entre as profissões dos alunos, destacam-se profissões mal remuneradas ou donas de casa, que trabalham somente em casa e por isso não possuem renda.

Sabemos somente a profissão desses alunos, não sabemos como são suas condições financeiras e se elas melhoraram ao longo do tempo em que ficaram fora da escola. A partir deste ponto de vista, percebemos a importância que dão à alimentação, que varia de acordo com suas condições financeiras e sua profissão.

Assim, analisando as narrativas, os alunos que frequentam o EJA são, em sua maioria, pessoas carentes que veem na escola uma oportunidade de mudança de vida e relacionam a escola a essa mudança e à construção de um futuro melhor. Quanto menos remunerado é seu trabalho, mais valor eles dão à alimentação, visto que, até hoje, os alunos mais carentes, muitas vezes têm na escola uma das únicas refeições de seu dia, chegando até mesmo, em alguns casos, a ser a única a que tem acesso.

Além das refeições, aparece também a questão da merenda de qualidade. Não basta somente disponibilizar merenda, mas a merenda deve ter uma boa qualidade. Nas narrativas é visível essa preocupação, visto que alguns alunos narram que saem correndo das salas de aula para irem formar a fila para se alimentar.

\section{A Relação Aluno/Professor}

Uma questão central e que se discute muito atualmente é a relação entre professores e alunos. Não aquela relação de poder e autoridade em que o aluno reproduz rigorosamente as lições ensinadas em sala pelo professor, nem a imposição de ideias prontas provindas de livros didáticos, mas, sim, uma relação em que as discussões e os conhecimentos sejam construídos quase que no mesmo nível. 0 aluno deixa de ser visto como sujeito passivo e passa a se tornar agente de sua própria história. 


\section{Críticas e Sugestões Relacionadas ao Professor}

Dentro da perspectiva acima, criamos uma categoria para tentar entender como os alunos veem ou como seriam os professores ideais para eles. As narrativas sugerem a contratação de novos e melhores professores, como também fazem críticas aos professores atuais, o que, com certeza, está ancorado em suas experiências vividas em sala de aula ou em relação aos filhos. Cito abaixo um exemplo de narrativa, dos alunos 1.15 I.A.A. e 1.73, que pede por mais professores: "[...] Para o bem dos alunos poderiam ponhar mais professores [...]" P. 15 L. 450 "[...] que os professores ensinase com mas fontade para que os alonos a prendese nas e dês uma boa intelijensia [...]" P. 39 L. 1227

Na narrativa do aluno 1.15 I.A.A., percebemos a importância dada não só ao professor, mas à quantidade de professores disponíveis. Assim, podemos considerar que, para estes alunos, a grande quantidade de professores é uma condição determinante para que o aprendizado ocorra de forma satisfatória.

Já no texto do aluno $1.73^{4}$, percebemos uma crítica direta ao professor, que, com certeza, não estava agindo da forma correta com seus alunos, faltando com suas obrigações de professor. Assim, para ele, o professor ideal seria aquele que tivesse boa vontade para com os alunos e prazer em ensinar, para que, assim, os alunos fossem incentivados e estimulados a aprender, conseguir aprimorar seus conhecimentos e "adquirir" a inteligência.

\section{A socialização Entre Alunos e Professores}

Levando em consideração que muitos alunos percebem e entendem a escola como um lugar onde ocorrem as relações sociais, os divertimentos, as conversas e a troca de experiências, é interessante perceber que essa socialização, na mentalidade dos alunos, não deveria acontecer somente entre eles, mas também entre os professores e os alunos. Deve-se a isso o fato de os alunos, por vezes, criticarem os professores mais rígidos e preferirem os mais espirituosos, divertidos etc. Como exemplos, cito os alunos 1.53 R.F. e 1.54 R.A.C.: "[...] Onde os professores e os aluno fossem grandes amigos [...]"

\footnotetext{
${ }^{4}$ Não consta na identificação as inicias do aluno, pois não nomeou seu exame.
} 
P. 32 L. 117 “[...] Eu queria que a professora fosse bem bozinha para mim [...]” P. 33 L. 1026

Eles possuem essa perspectiva de que é possível a amizade entre professores e alunos, sem que isso atrapalhe o bom rendimento em sala de aula. Até mesmo hoje, em nossas experiências enquanto professores, percebemos que muitas vezes as relações amigáveis e de cordialidade entre aluno e professor permitem que se trabalhe melhor com a turma, numa relação que ultrapassa a autoridade, tornando-se uma relação de afetividade e quase de igualdade, com ressalvas, é claro.

Portanto, aquele sistema em que a autoridade do professor é o motivo pelo qual os alunos the devem respeito, em que o fato de o professor ter 0 conhecimento é o que o eleva a condição de transmissor de conteúdos e ensinamentos não funciona mais. O mundo está em constante transformação, a tecnologia nos surpreende a cada dia, e nossos alunos fazem parte desse processo. 0 professor deve saber adequar-se a isso para que use essas intensas mudanças a seu favor e a favor de suas práticas pedagógicas, para que assim o conhecimento possa ser discutido, questionado e construído, e não apenas reproduzido.

Podemos dizer que os alunos possuem ideias variadas sobre a escola e sobre qual seria a ideal para ele e para os outros, visto que não pensam somente em si, mas também em outras pessoas. Nas narrativas encontramos alunos que tratam da escola apenas como um espaço físico espaçoso, limpo e bonito; outros relacionam a escola à socialização; outros, à segurança, etc. Em relação às funções da escola, aparecem a alfabetização, a preparação para a vida, para o emprego e a esperança de um futuro melhor.

As narrativas sugerem que, mesmo com as diferenças na maneira de pensar e entender a escola, existe uma convergência entre elas. Todos os alunos depositam muita confiança na escola e criam seus textos a partir desse sentimento, para descrever a escola com que sonham.

É importante analisar essas narrativas justamente para tentar entender como esses alunos pensam e imaginam a escola, para que, através disso, possamos repensar a escola e nossas práticas pedagógicas. 


\section{Considerações Finais}

Em suma, podemos dizer que, através das narrativas, os estudantes apresentam diversas ideias e concepções em relação à escola e ao espaço escolar que para eles seriam os ideais. Categorizando as narrativas em duas grandes classes, "as representações da escola ideal” e "as funções a serem desempenhadas pela escola ideal", pudemos analisar como os estudantes da Educação de Jovens e Adultos de algumas cidades do Norte Velho Paranaense concebem qual seria o espaço escolar ideal para sua aprendizagem e as principais funções que a escola deve desempenhar. O que nos chamou a atenção, e que perpassa uma grande parte das narrativas das duas categorias, em sua essência ou como consequência de suas atribuições, é a escola como tendo uma missão salvadora. Temos a impressão de que os alunos enxergam na escola a resolução de uma grande parte não só dos seus problemas, visto que são adultos em fase de escolarização, mas também dos problemas de outros indivíduos que ainda passarão por ela, principalmente quando relacionada ao mercado de trabalho e à quebra dos preconceitos.

É evidente que a escola exerce uma função social de extrema relevância, inclusive nas questões apontadas pelos alunos - mercado de trabalho, conquista de uma vida melhor, entre outros -, mas nos parece que determinadas narrativas concebem a escola como uma instituição que salva sozinha, alheia a outros setores e instituições sociais, políticas e administrativas.

Sabemos que ainda há uma longa trajetória pela frente, para que nossas escolas sejam locais ideais para o ensino e aprendizagem, mas saber o que nossos estudantes pensam em relação a esse espaço é de vital importância, até mesmo porque são raros os trabalhos que se dedicam à reflexão das ideias dos estudantes da Educação de Jovens e Adultos. Esta é, em nossa singela opinião, a principal contribuição deste trabalho. 


\section{Referências}

BARDIN, Laurence. Análise de conteúdo. Lisboa: Ed. 70, 1977.

GINZBURG, Carlo. Sinais: raízes de um paradigma indiciário In: . Mitos, emblemas, sinais: morfologia e história. Tradução de Frederico Carotti. São Paulo: Companhia das Letras, 1990.

MATTOZI, Ivo. A história ensinada: educação cívica, educação social ou formação cognitiva? In: CONGRESSO: O ENSINO DA HISTÓRIA: PROBLEMAS DE DIDÁCTICA E DO SABER HISTÓRICO, 1998, Lisboa. Actas... Lisboa: Associação de Professores de História, 1998. (O Estudo da História, n. 3).

MELO, Maria do Céu de. O conhecimento tácito histórico dos adolescentes. 2003. Tese (Doutorado em Educação) - Universidade do Minho, Braga, 2003.

MORAES, Roque. Uma tempestade de luz: a compreensão possibilitada pela análise textual discursiva. Revista Ciência \& Educação, Bauru, v. 9, n. 2, p. 191-211, 2003.

SÊGA, Rafael Augustos. O conceito de representação social nas obras de Denise Jodelet e Serge Moscovici. Revista Anos 90, Porto Alegre, n. 13, p. 128-133, jul. 2000. 